\title{
Cervical Localization of a Mature Pluritissular Teratoma: Case Report
}

\section{Ngouoni Gérard Chidrel ${ }^{1 *}$, Otouana Dzon HB ${ }^{1}$, Itiere Odzili FA', Diembi Sylvain ${ }^{2}$, Mouamba FG ${ }^{3}$, Peko JF ${ }^{3}$ and Ondzotto ${ }^{1}$}

${ }^{1}$ ENT Service, Brazzaville University Hospital, Marien Ngouabi University,

Brazzaville, Republic of the Congo

${ }^{2}$ ENT Department, Hospital A. Sice. Pointe-noire, Marien Ngouabi University,

Brazzaville, Republic of the Congo

${ }^{3}$ Department of Pathological Anatomy and Cytology, Brazzaville University

Hospital, Marien Ngouabi University, Brazzaville, Republic of the Congo

*Corresponding Author: Doctor Ngouoni Gérard Chidrel, ENT Service, Brazzaville

University Hospital, Marien Ngouabi University, Brazzaville, Republic of the Congo.
Received: June 21, 2021

Published: July 26, 2021

(C) All rights are reserved by Ngouoni Gérard

Chidrel., et al.

\section{Abstract}

The teratoma is a tumor originating from pluripotential cells and composed of a great diversity of tissues foreign to the organ. Its cervical localization is rare. The management remains surgical in order to avoid complications and reduce the risk of malignant transformation. We report a case of low cervical localization in an 11-year-old girl. Clinical examination and ultrasound of the tumour evoked goiter. The histopathological results, after total excision of the operating room, concluded to a mature pluritissular teratoma. The rare possibility of a recurrence of this benign tumor justifies a long-term follow-up of this young patient.

Keywords: Teratoma; Cervical; Mature; Pluritissular

\section{Introduction}

The teratoma is a tumor originating from pluripotential cells and composed of a great diversity of tissues foreign to the organ or anatomical site on which it occurs [1,2]. Il is a rare tumor, $1 / 40000$ births. Cervical localization accounts for 1.5 - 5\% of all localizations $[3,4]$. It is associated with a high mortality rate of up to $80 \%$ in the neonatal period due to airway obstruction [5]. His diagnosis is often antenatal, ultrasound or magnetic resonance imaging (MRI). Management must be urgent and multidisciplinary to avoid complications related to compression, but also to reduce the risk of carcinological [6]. We present a case with antero-cervical localization observed in the ENT department of the Brazzaville University Hospital.

\section{Case Observation}

p. N, female, aged 11 years, who had consulted for a voluminous low antero-cervical mass. This mass, initially not very voluminous, would evolve for 1 year. She had clinical characteristics of a thyroid tumor: sitting in the thyroid area, mobile to swallowing. The mass was renitent at the palpation, bumpy, tense, painless, measuring 12 $\mathrm{cm}$ in diameter on its major axis. The rest of the somatic examination was normal. The interrogatory did not find a notion of dysphonia, nor of dyspnea. physical examination did not reveal any other associated malformation.

Inflammatory blood tests (blood count, C-reactive protein), thyroid hormones (TSH, FT4, FT3) and markers of certain embryonic 
tumors such as alfa-foetoprotein and beta-hCG (beta fraction of chorionic hormones gonadotrophiques) were normal.

Cervical ultrasound revealed a polycystic goiter. Chest X-ray was normal.

The surgical decision was made for the realization of an extracapsular total thyroidectomy. The intervention made it possible to highlight per operatively a juxta-thyroid cystic formation, pediculated, of $11 \times 8 \times 3 \mathrm{~cm}$. Complete excision of the tumor was done by progressive dissection.

Histological examination of the excision piece showed: a cystic tumor proliferation, whose wall is composed of several heterologous tissues, including cartilaginous, bony, glandular salivary type and many others. There was no sign of malignancy. This result confirmed the diagnosis of a mature multitissular terome.

Post-operative follow-up, with a two-year setback, did not note a recurrence.

\section{Discussion}

Very different from dysembryoplasia, the teratoma contains tissues foreign to the region that houses it and resembling those that follow one another during development, from the embryonic stage to the adult stage. The teratoma is a germ cell neoplasm made of a differentiation of three primordial leaflets, ectoblastic, endoblastic and mesoblastic. It almost always presents as a tumor [1,7-9]. Cervical teratoma is an exceptional congenital tumor. It most commonly develops in the thyroidal t-area (our observation). It is considered come a thyroid cyst [10-12]. The intervention will therefore make it possible to recognize the juxta-thyroid character of the cystic mass. Localization in the submandibular area was also described [9]. Azizkhan RG [3] reported that the cervical teratoma is often accompanied by other malformations. On the other hand, in our observation, the cervical teratoma was not associated with other malformations. In some cases, it is a voluminous, congenital tumor, incompatible with life due to its compressive tendency of the aero-digestive tract and responsible for respiratory distress. The cervical teratoma also has an unsightly character [4]. On the other hand, when the tumor is small, it can pass into its perceived and then quickly take a considerable development. This most often explains the late consultation.
Ultrasound was the first-line examination, due to the disadvantaged socio-economic context. It is indicated before any mass increasing in volume in order to search for its malformative etiology. It highlights a cervical mass with a tissue and cystic component, with, sometimes, calcifications. This examination is usually supplemented by magnetic resonance imaging (MRI), which gives more details and eliminates other diagnoses [6]. These data change surgical management and prognosis.

The physical examination as well as the ultrasound results (in our observation), which have oriented towards a polycystic goiter, show that itis a tumor requiring to be always better explored.

Cervical teratomas should be differentiated from latero-cervical fistulas, gill cysts, latero-cervical tonsdalaloid cysts, cervical congenital cystic hygroma, cervical hemolymphangiomas, thyroid tumors, inflammatory adenopathies (or blood diseases), salivary gland tumors, lymph node metastases of carcinomas or sarcomas, and other tumors such as leiomyosarcomas, hemangiosarcomas, fibrosarcoma's, osteosarcomas and mesenchymomas [13,14].

The diagnosis of teratoma requires insurance regarding its benign or malignant nature, which would guide the therapeutic attitude. In its benign form, all the tissues present are mature and have reached the end of their differentiation [1]. If the existence of some cellular immaturities does not have great prognostic importance, it is not the same for the more marked cellular atypia or other usual criteria of malignancy [15]. Our case, corroborates with the literature, reported a cystic tumor proliferation consisting of cartilaginous, bony, glandular tissues of salivary type and well autres. The term dermoid cyst is applied to mature cystic teratomas essentially composed of epidermal tissue associated with pilosebaceous appendages [16]. The mature teratoma most often contains derivatives of the ectodermal layer such as the skin, hair and sebaceous glands. Mais, any other tissue can exist in particular thyroid tissue, found in $15 \%$ of cases [17].

Surgical excision was easy because, the teratoma has a plane of cleavage with respect to the tissues and organs of neighborhood. It has only weak vascular connections $[18,19]$. It is necessary to carry out a total excision of the tumor and to make multiple removals so as not to mass undifferentiated, malignant area whose presence can change the prognosis $[20,21]$. Hence the importance of the extemporaneous, not available in our country. 
The evolution over time of the levels of alfa-foetoprotein is necessary for the follow-up of patients with cervical teratoma. Their evaluation or maintenance at high values should raise fears of the existence of a malignant contingent in the form of recurrence and/ or metastasis. In the case of benign lesions, complete excision allows a gueridon which should not exclude regular clinical and biological follow-up. Faced with a malignant lesion, rare and can worsen the prognosis of the disease, surgery will be supplemented by chemotherapy and/or radiotherapy [22].

\section{Conclusion}

The existence of a low antero-cervical mass poses the problem of etiological diagnosis of a thyroid tumor, dysembryoplasia or teratoma whose histological analysis of the excision piece will best specify the tumor nature. In the case of a benign teratoma, although the excision is complete, clinico-biological monitoring should be instituted.

\section{Bibliography}

1. Cabanne F and Bonenfant JL. "Pathology anatomy: Principles of general pathology, special pathology and anatomie pathology". Les presses de l'université Laval Maloine (1986): 1346.

2. Ksia A., et al. "Cervical teratoma in children Cervical teratoma in a child". Pediatric Archives 20.10 (2013): 1133-1138.

3. Azizkhan RG., et al. "Diagnosis, Management, and Outcome of Cervicofacial Teratomas in Neonates: A Childrens Cancer Group Study". Journal of Pediatric Surgery 30.2 (1995): 312316.

4. Mishra N., et al. "Case of nasopharyngeal teratoma: challenges in the management". BMJ Case Reports 12.9 (2019): 230105.

5. Mohamed Rami., et al. "Cervical teratoma: about 2 cases". Pan African Medical Journal 12.91 (2012): 1-8.

6. Belaloui MO., et al. "Congenital cervical teratoma”. The Letter of ENT and Cervicofacial Surgery 328 (2012): 30-31.

7. Kisiel MA., et al. "A rare case of benign teratoma of the facial fronto-temporal region in adult male". Polski Merkuriusz Lekarski 47.280 (2019): 150-152.

8. Lakhoo K. "Neonatal teratomas". Early Human Development 86 (2010): 643-647.
9. Kisiel MA., et al. "A rare case of benign teratoma of the facial fronto-temporal region in adult male". Polski Merkuriusz Lekarski 47.280 (2019): 150-152.

10. Warrior Y. "Surgery of malformative and congenital diseases of the neck". In treated surgical technique ENT and cervicofacial: neck and oral cavity. Masson 4 (1988): 315.

11. Truffert P. "Diseases of the neck". In Truffert P, Bonnet-Roy FL, Rossert AZ et al. otolaryngology. Medical-surgical collection with annual revision. Medical Editions". Flammarion (1948): 903.

12. Tian Z., et al. "Surgical treatment of benign mediastinal teratoma: summary of experience of 108 cases". Journal of Cardiothoracic Surgery 15.1 (2020): 36.

13. Roth A. "Congenital cervical benign teratoma”. Annales Otolaryngology 101 (1984): 603-606.

14. Maruguchi H., et al. "Mature teratoma treated as lymphatic malformation for 5 years: a case report and literature review". The Journal of Plastic Surgery and Hand Surgery 6.1 (2019): 63-68.

15. Dehner LP. "Pediatric surgical pathology". Second edition 1987; Edition. Williams Wilkins, Baltimore (USA) (1987): 160.

16. Nogales F., et al. "Germ cell tumours". In Tumours of the breast and female genital organs. Edition Tavassoli FA et Devilee P. World Health Organization Classification of Tumours. IARC Press (2003): 163-175.

17. Russel P., et al. "Ovarian tumors: classification and clinical perspectives”. In Robboy SJ, Anderson MC, Russel P: pathology of the Female Genital Tract. Philadelphia PA, Chrurchill Livingston (2002): 527-538.

18. Hirose S., et al. "Spectrum of Intrapartum Management Strategies for Giant Fetal Cervical Teratoma”. Journal of Pediatric Surgery 38.3 (2003): 446-450.

19. Hasiotoua Maria., et al. "Congenital cervical teratomas". International Journal of Pediatric Otorhinolaryngology 68.9 (2004): 1133-1139.

20. Azizkhan RG., et al. "Diagnosis, Management, and Outcome of Cervicofacial Teratomas in Neonates: A Childrens Cancer

Citation: Ngouoni Gérard Chidrel., et al. "Cervical Localization of a Mature Pluritissular Teratoma: Case Report". Acta Scientific Otolaryngology 3.9 (2021): 129-132. 
Group Study". Journal of Pediatric Surgery 30.2 (1995): 312-

316.

21. Shefali I Shah and Licameli Greg. "Congenital cervical teratoma: Airway management and complications". OtolaryngologyHead and Neck Surgery 124 (2001): 53-55.

22. Le Fèvre C., et al. "Metastatic mediastinal mature teratoma with malignant transformation in a young man with an adenocarcinoma in a Klinefelter's syndrome: Case report and review of the literature". Radiotherapie Du Cancer 22.3 (2018): 255263.

Volume 3 Issue 9 September 2021

(C) All rights are reserved by Ngouoni Gérard Chidrel., et al. 